\title{
Vascular Complications in Diabetes Mellitus
}

\author{
Ighodaro OM* and Adeosun AM \\ Department of Biochemistry, Lead City University, Nigeria
}

*Corresponding author: Ighodaro OM, Department of Biochemistry, Lead City University, Nigeria

Submission: 海 September 14, 2017; Published: 海 October 24, 2017

\begin{abstract}
Vascular complications are pivotal to the devastating effects of diabetes mellitus, and occur as a result of hyperglycemia engendered link between the disease and oxidative stress. In the diabetics, vascular tissues are damaged due to hyperglycemia-mediated free radicals, particularly through oxidation of essential biomoecules such as DNA, proteins and lipids in these tissues. Depending on the type of blood vessels affected, there are different categories of diabetic complications. The two major ones are micro vascular and macro vascular complications. The latter indicates damage to large blood vessels, while the former describes damage to small blood vessels. This mini-review provides some important information on vascular complications in the diabetics.
\end{abstract}

Keywords: Vascular; Complications; Diabetes mellitus

\section{Introduction}

Complication is described as a confused condition arising out of previous conditions. Diabetic complications are increasing with the severity of the disease [1]. Most of the complications in diabetes are similar regardless of the type of diabetes. These complications account for the major morbidity and mortality associated with both type 1 and type 2 diabetes mellitus [2,3]. Diabetic complications are generally categorized into macro vascular and micro vascular conditions. According to Smelters and Bare [4], macro vascular dysfunctions or complications results from atherosclerotic changes in the larger blood vessels. Different types of macro vascular diseases (coronary artery disease, cerebral vascular disease and peripheral vascular disease) may result, depending upon the location of the atherosclerotic lesions [5]. Cardiovascular disease (coronary artery disease) is the major macro vascular complication and includes mainly myocardial infarction and stroke [6,7]. The risk for cardiovascular disease is 4-8 times higher for people with type 1 diabetes [8]. The major micro vascular complications are diabetic retinopathy, diabetic nephropathy and diabetic neuropathy [6]. These are the diseases of small blood vessels where the basement membrane in the capillaries and arterioles thickens [4].

\section{Complications of diabetes mellitus}

Vascular complications in diabetes arise from persistent chronic hyperglycemia. These complications are generally categorized into macro vascular and micro vascular conditions (Figure 1). The risk factors for diabetes and associated complications are depicted in Figure 2. Hyperglycemia appears to the primary cause of micro vascular complications whereas macro vascular complications may involve other factors besides hyperglycemia [9] (Figure 1 \& 2).
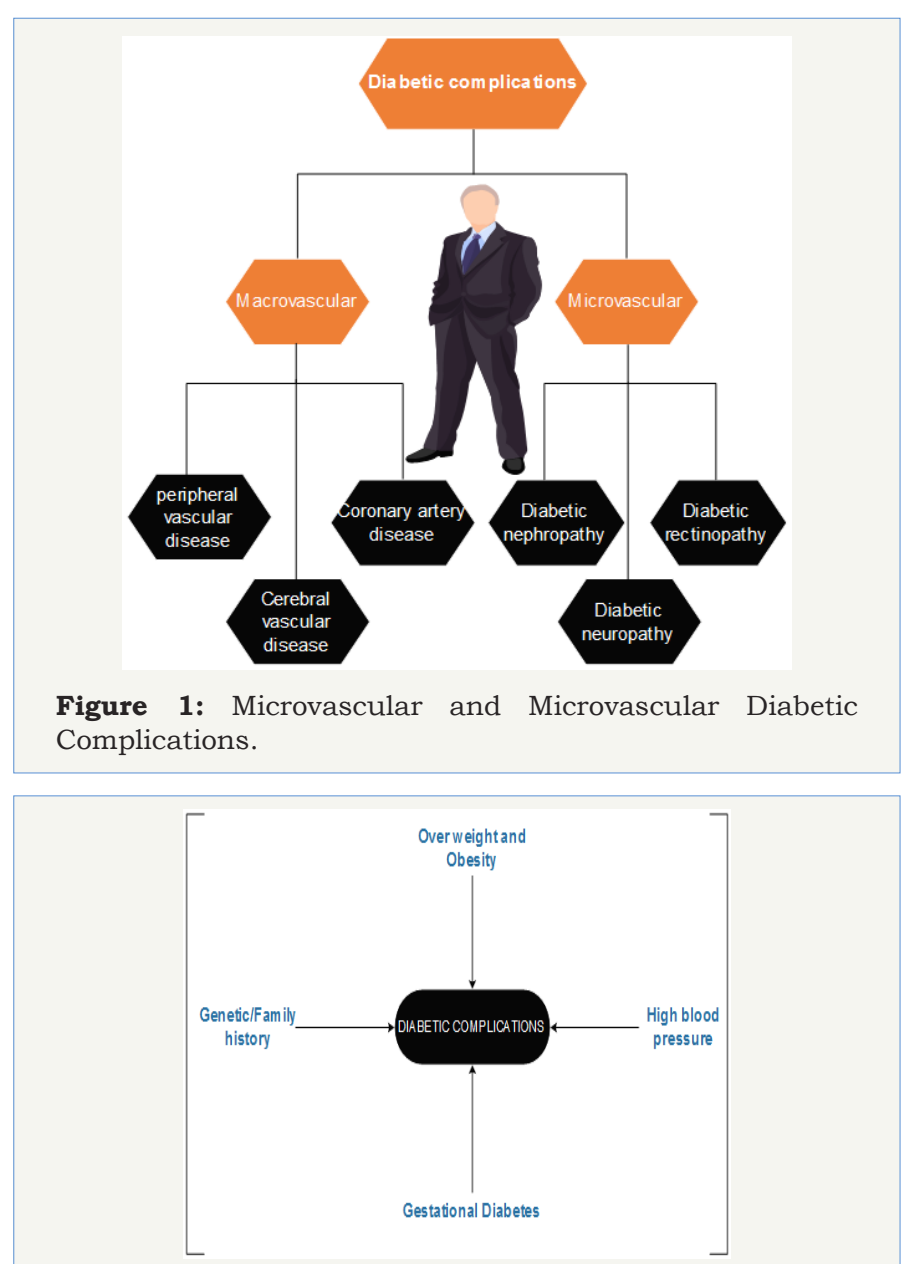

Figure 2: Risk factors and complication of diabetes. 
Macrovascular complications: Smeltzer and Bare [4] described macro vascular diseases as atherosclerotic changes in the larger blood vessels. This invariably means that the central mechanism for macro vascular complications is atherosclerosis [10]. The process involves chronic inflammation and injury to the arterial wall in the peripheral or coronary vascular system. Acute vascular infarction subsequently, results from accumulation and rupture of oxidized low density lipoprotein (LDL) particles in the endothelial wall of arteries. The main macro vascular complications associated with diabetes are cardiovascular diseases (mostly coronary artery disease), cerebral vascular disease and peripheral vascular disease.

Coronary artery disease: Coronary artery disease (CAD) which was formerly considered as a cholesterol storage disease is now understood to be an inflammatory disorder characterized by atherosclerotic changes in the coronary arteries. The whole process represents a complex interaction of various risk factors including the arterial cell wall and the blood as well as the molecular messages that they exchange [11]. CAD is a major health concern and the leading cause of death in individuals with type 2 diabetes $[12,13]$. CAD is usually asymptomatic and often leads to sudden cardiac death of patient [14]. The most common of CAD in individuals with diabetes is myocardial infarctions. It probably account for about $60 \%$ of all diabetes associated- mortality. Lack of early warning signs makes this complication very deadly [15].

Cerebral vascular disease: Cerebral vascular disease occurs due to atherosclerotic changes in cerebral blood vessels. It often involves the formation of an embolus in a different location in the vascular system which then lodges in a cerebral blood vessel. The formed embolus due to blockage of blood flow to any part of the cerebral region can cause transient ischemic attacks and strokes. This pathological situation is complicated in patients with diabetes. In fact, recovery from stroke may be hampered in diabetic individuals with extremely high blood glucose concentration at the time of diagnosis [15]. Effective glycemic control is therefore vitally important in the prevention of cerebral vascular disease as a diabetic complication.

Peripheral vascular disease: Peripheral vascular disease is also referred to as lower extremity arterial disease (LEAD). It occurs as a result of atherosclerotic changes in the large blood vessels of the lower extremities and is clinically identified by intermittent claudicating and /or absence of peripheral pulse in the lower regions of the body such as the legs and feet [4]. Chronic hyperglycemia which is characteristic of diabetes engenders oxidative cell environment which ultimately damage peripheral blood vessels and impairs blood flow to the lower extremities of the body. Severe arterial occlusions in the lower extremities are principally responsible for cases of gangrene and amputations in diabetic patients [4].

Micro vascular complications: Micro vascular complications are diseases of small blood vessels usually developed in diabetes.
The major ones are retinopathy, nephropathy and neuropathy and are respectively leading causes of blindness, end-stage renal disease and various painful neuropathies [6]. The incidence of micro vascular lesions involves the thicken of the basement membrane in the capillaries and arterioles of blood vessels of the retina and kidney $[4,16]$.

Diabetic retinopathy: Diabetic Retinopathy is one of the micro vascular complications experienced by individuals with prolong diabetes. It usually causes visual impairment and sometimes total blindness [17]. Diabetic retinopathy is the leading cause of blindness in the United States of America among all categories of diabetic patients (old and young). Diabetic retinopathy can be classified into background retinopathy and preproliferative retinopathy which are respectively characterized by partial occlusion of the small blood vessels in the retina with formation of micro aneurysms in the capillary wall [18] and total occlusion of the small blood vessels in the retina leading to destruction of retinal capillaries [19].

Diabetic Nephropathy: Diabetic nephropathy is an endstage renal disease with an incidence rate of 40 percent of all patients with type 2 diabetes [20]. It is the leading cause of endstage renal disease in the United States and other parts of the globe like Europe, Japan [21]. Early detection and employment of appropriate renoprotective treatments of susceptible patients is very important. Type 2 Diabetic patients with microalbuminuria are on the average 15 times more susceptible to compared to those with normoalbuminuria [22,23] Where as, about $29 \%$ of all patients with type 1 diabetes develop persistent microalbuminuria. Patients with diabetic nephropathy often rely on kidney dialysis or transplantation.

Diabetic Neuropathy: Diabetic neuropathy constitutes a wide range of abnormalities involving both somatic and autonomic nervous system [24]. It is described as a group of diseases that damage the nerves, including peripheral (sensory motor), autonomic and spinal nerves. Chronic hyperglycemia over a period of years has been accounted as the cause of neuropathy [25]. Neuropathy may be sensory motor neuropathy or autonomic neuropathy. While the former affects the distal portion of the nerves, more especially the lower extremities [26], the latter engender a broad range of dysfunctions affecting almost every organ and system of the body. Glycemic control and tissue transplant from the islets of Langer Hans can be used to delay or prevent the development of neuropathy [27].

\section{Conclusion}

Diabetic complications worsen diabetes cases, increase mortality rate of the disease and puts enormous burden on health care resources of countries. Therefore, efforts geared at preventing these complications will greatly lessen the devastating effects of diabetes and its complications on the global populace.

\section{References}

1. Brownlee M (2001) Biochemistry and molecular cell biology of diabetic complications. Nature 414(6865): 813-820. 
2. Daneman D (2006) Type 1 diabetes. Lancet 367(9513): 847-858.

3. Fowler MJ (2008) Microvascular and macrovascular complications of diabetes. Clinical diabetes 26(2): 77-82.

4. Smeltzer SC, Bare BG (1992) Assessment of cardiovascular function. Medical Surgical Nursing.

5. Gupta Y, Kalra B, Baruah MP, Singla R, Kalra S (2015) Updated guidelines on screening for gestational diabetes. Int J Womens Health 7: 539-550.

6. American Diabetes Association(2010) Introduction. Diabetes Care 33(S1): S1-S2.

7. Martín-Timón I, Sevillano-Collantes C, Segura-Galindo A, del CañizoGómez FJ (2014) Type 2 diabetes and cardiovascular disease: have all risk factors the same strength? World J Diabetes 5(4): 444-470.

8. Soedamah-Muthu SS, Fuller JH, Mulnier HE, Raleigh VS, Lawrenson RA et al. (2006) High risk of cardiovascular disease in patients with type 1 diabetes in the UK: a cohort study using the general practice research database. Diabetes Care 29(4): 798-804.

9. Giorgino F, Leonardini A, Laviola L (2013) Cardiovascular disease and glycemic control in type 2 diabetes: now that the dust is settling from large clinical trials. Ann N Y Acad Sci 1281(1): 36-50.

10. Lazo-de-la-Vega ML, Fernández-Mejía C (2013) Oxidative stress in diabetes mellitus and the role of vitamins with antioxidant actions. In Oxidative Stress and Chronic Degenerative Diseases-A Role for Antioxidants InTech.

11. Libby P, Theroux P (2005) Pathophysiology of coronary artery disease. Circulation 111(25): 3481-3488.

12. Grundy SM, Benjamin IJ, Burke GL, Chait A, Eckel RH, et al. (1999) Diabetes and cardiovascular disease: a statement for healthcare professionals from the American Heart Association. Circulation 100(10): 1134-1146.

13. Inzucchi SE, Bergenstal RM, Buse JB, Diamant M, Ferrannini E, et al. (2012) Management of hyperglycemia in type 2 diabetes: a patientcentered approach: position statement of the American Diabetes Association (ADA) and the European Association for the Study of Diabetes (EASD). Diabetes Care 35(6): 1364-1379.

14. Jouven X, Lemaitre RN, Rea TD, Sotoodehnia N, Empana JP, et al. (2005) Siscovick DS. Diabetes, glucose level, and risk of sudden cardiac death. Eur Heart J 26(20): 2142-2147.
15. Smeltzer SC, Bare BG (1996) Brunner \& Suddarth's Textbook of Medical Surgical Nursing. In: Hartono A, Kuncara HY, Siahaan ESL, Trans (Eds.), $\left(8^{\text {th }}\right.$ edn) Jakarta: EGC, Jakarta.

16. Forbes JM, Cooper ME (2013) Mechanisms of diabetic complications. Physiol Rev 93(1): 137-188.

17. Barton K, Hitchings RA (2013) Introduction. Medical Management of Glaucoma: 1-32.

18. Wilkinson CP, Ferris FL, Klein RE, Lee PP, Agardh CD, et al. (2003) Proposed international clinical diabetic retinopathy and diabetic macular edema disease severity scales. Ophthalmology 110(9): 16771682.

19. Danis RP, Davis MD (2008) Proliferative diabetic retinopathy. In Diabetic Retinopathy. Humana Press, New York, USA, pp. 29-65.

20. Shilubane HN (2009) Knowledge of patients and family members regarding diabetes mellitus and its treatment (Doctoral dissertation).

21. Parving H-H, Østerby R, Ritz E (2000) Diabetic nephropathy. In: Brenner BM (Edt.), The kidney. ( $6^{\text {th }}$ edn), Philadelphia: WB Saunders, USA, pp. 1731-1773.

22. Parving HH, Lehnert H, Bröchner-Mortensen J, Gomis R, Andersen S, et al. (2001) The effect of irbesartan on the development of diabetic nephropathy in patients with type 2 diabetes. N Engl J Med 345(12): 870-878.

23. Adler AI, Stevens RJ, Manley SE, Bilous RW, Cull CA, et al. (2003) Holman RR, UKPDS Group. Development and progression of nephropathy in type 2 diabetes: the United Kingdom Prospective Diabetes Study (UKPDS 64). Kidney Int 63(1): 225-232.

24. Yagihashi S (1995) Pathology and pathogenetic mechanisms of diabetic neuropathy. Diabetes/Metabolism Research and Reviews 11(3): 193225 .

25. Yagihashi S, Yamagishi SI, Wada R (2007) Pathology and pathogenetic mechanisms of diabetic neuropathy: correlation with clinical signs and symptoms. Diabetes Res Clin Pract 77(3): S184-S189.

26. Sahakyan K, Klein BE, Lee KE, Myers CE, Klein R (2011) The 25-year cumulative incidence of lower extremity amputations in people with type 1 diabetes. Diabetes care 34(3): 649-651.

27. Robertson RP (2004) Islet transplantation as a treatment for diabetes-a work in progress. N Engl J Med 350(7): 694-705. 